\title{
Penerapan Viewboard Status Validasi Berbasis Yii Framework pada PESSTA+ di Perguruan Tinggi
}

\author{
The Application of Viewboard Validation Status Based Yii Framework \\ on PESSTA+ In College
}

\author{
Untung Rahardja*1, Indri Handayani ${ }^{2}$, Yoyo Syoifana ${ }^{3}$ \\ 1,2,3 STMIK Raharja Jurusan Sistem Informasi \\ E-mail: *11 untung@raharja.info, ${ }^{2}$ indri@raharja.info, ${ }^{3}$ yoyo@raharja.info
}

\begin{abstract}
Abstrak
Dengan perkembangan yang sangat pesat di dunia telekomunikasi yang di tandai dengan era digital, lebih tepatnya di bidang Teknologi Informasi dan Komunikasi. Penelitian mengacu pada sistem PESSTA+ (Penilaian Sidang Skripsi dan Tugas Akhir Plus), PESSTA+ merupakan system yang di gunakan sebagai media submit validasi penilaian objektif sebagai persyaratan sidang Skripsi, dapat di akses dimana saja dan kapan saja. Bertujuan untuk memudahkan mahasiswa dalam menyelesaikan 10 poin penilaian objektif. Perlu adanya data untuk menggambarkan pengukuran performa pada suatu system, agar dapat di rasakan manfaatnya dari system tersebut. Viewboard merupakan sistem aplikasi yang dapat memonitoring ataupun menampilkan sebuah informasi dalam bentuk grafik sehingga memudahkan pengguna dalam mengendalikan dan menetapkan tujuan yang akan di capai. Selain itu Viewboard juga dapat di jadikan sarana untuk mengevaluasi proses pada sistem yang berjalan saat ini. Dengan adanya Viewboard di harapkan dapat memecahkan permasalahan yang ada sebelumnya yaitu memberikan informasi mengenai performa mahasiswa pada status validasi penilaian objektif di sistem PESSTA+.
\end{abstract}

Kata Kunci - Penilaian Objektif, PESSTA+, Validasi, Viewboard

\begin{abstract}
With the rapid development in the world of telecommunications characterized by the digital era, especially in the field of Information and Communication Technology. The study refers to the PESSTA + system (Assessment of Thesis and Final Assemblies Plus), PESSTA + is a system that is used as a media submit validation of objective assessment as a thesis trial requirement that can be accessed anywhere and anytime. Aims to enable students to meet 10 objective assessments. Need the data to describe the performance measurement on a system, in order to feel the benefits of the system. Viewboard is an application system that can monitor or display an information in the form of graphs so as to facilitate the user in controlling and setting goals to be achieved. In addition, the Viewboard can also be used as a means to evaluate the process on the current system. With the Viewboard is expected to solve the existing problems that are providing information on student performance on the validation status of objective assessment in PESSTA + system.
\end{abstract}

Keywords - The Assessment of Objective, PESSTA+, Validation, Viewboard 


\section{PENDAHULUAN}

PESSTA+ (Penilaian Sidang Skripsi dan Tugas Akhir Plus) adalah sistem yang di gunakan sebagai media submit validasi penilaian objektif sebagai persyaratan sidang skripsi yang dapat di akses dimana saja dan kapan saja. Dengan adanya PESSTA+ diharapkan dapat memudahkan mahasiswa dalam memenuhi 10 poin penilaian objektif sebagai persyaratan sidang skripsi.

Pada sebuah sistem di perlukan adanya data untuk menggambarkan performa mahasiswa atau dosen sebagai pengguna. Oleh karena itu suatu sistem perlu menerapkan sebuah viewboard yang dapat menampilkan data yang bersifat informatif yang di tujukan bagi para pengguna sistem tersebut. Selain juga dapat menampilkan informasi mengenai performa, sistem ini juga dapat memberikan hasil yang di jadikan tolak ukur kinerja pengguna.

Viewboard merupakan sebuah aplikasi sistem yang dapat menampilkan data informasi, dalam hal ini berbentuk grafik dan tabel yang sangatlah penting bagi pengguna pada suatu sistem. Untuk dapat mengendalikan suatu sistem agar mencapai tujuan atau target yang di inginkan yang sudah di tetapkan.

Menurut Rahardja, dkk, (2016:252), Viewboard merupakan sistem aplikasi yang menampilkan informasi dalam bentuk panel yang sangat penting bagi pemimpin instintusi pendidikan dalam mengendalikan dan membawa organisasinya mencapai sasaran, tujuan, visi dan misi yang telah ditetapkan.

Penerapan viewboard pada PESSTA+ di poin status validasi Penilaian objektif bertujuan untuk mengelola informasi mengenai status validasi penilaian objektif. Penilaian objektif mencakup poin-poin penting yang harus di capai mahasiswa untuk memenuhi persyaratan sidang Skripsi. Untuk menyelesaikan penilaian objektif mahasiswa harus memenuhi 10 poin penilaian objektif yang sudah di tentukan pada Perguruan Tinggi Raharja.

Menurut Riyanto (2015:7), Validasi adalah konfirmasi melalui bukti-bukti pemeriksaan dan telah sesuai dengan tujuan pengujian. Validasi harus dilakukan terhadap metode non-standar dan metode yang dikembangkan laboraturium. Rentang ukur dan akurasi dapat diperoleh dari hasil validasi metode yang sesuai dengan kebutuhan customer.

Yii Framework yang berlogo seperti pada Gambar 1, merupakan jenis PHP berbasis komponen, berkinerja tinggi dalam pengembangan aplikasi web berskala besar. Yii Framework merupakan kerangka sistem atau merupakan program yang sudah jadi sehingga pengguna Yii dapat langsung mengolah ataupun mengembangkan sistem yang di inginkan.

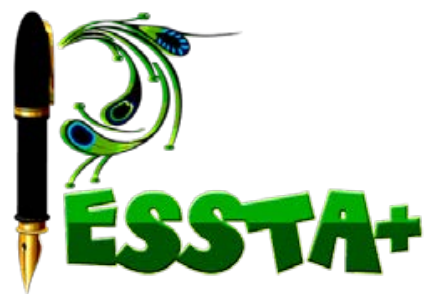

Gambar 1. Logo PESSTA+

\section{METODE PENELITIAN}

Metode dalam perancangan viewboard ini mempunyai tujuh tahapan sesuai dengan tahapan pengembangan sistem perangkat lunak, yaitu definisi masalah, analisa kebutuhan, perencanaan, pembuatan prototype, pemeliharaan, pengujian dan implementasi. Berikut ini adalah perancangan metode penelitian yang di gunakan, ditunjukkan pada Gambar 2. 


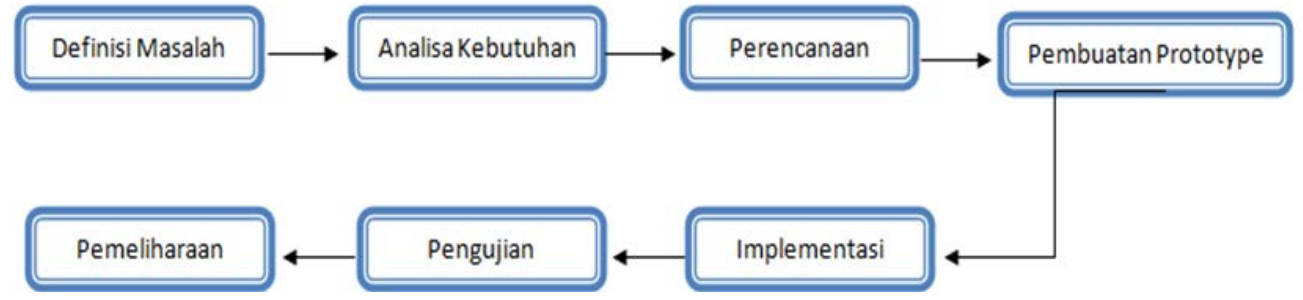

Gambar 2. Tahapan Penelitian

Keterangan:

1. Definisi Masalah, yaitu melakukan investigasi secara lebih detail dan tertata agar dapat mengetahui letak permasalahan alur yang sedang berjalan.

2. Analisa Kebutuhan, setelah melakukan investigasi masalah serta sudah mengetahui letak permasalahannya selanjutnya menganalisa kebutuhan apa saja yang dibutuhkan.

3. Perencanaan, selanjutnya melakukan perencanaan penerapan Viewboard status validasi Penilaian Objektif pada sistem PESSTA+.

4. Pembuatan Prototype, Setelah rancangan terkonsep, selanjutnya adalah mengaplikasikannya dengan cara membuat prototype atau gambaran rencana Viewboard status validasi Penilaian Objektif pada sistem PESSTA+ agar lebih mudah di pahami.

5. Implementasi, Apabila tahapan-tahapan sebelumnya telah selesai dilakukan dan benar maka selanjutnya adalah penerapan dari prototype yang telah dibuat pada sistem.

6. Pengujian, Pengujian ini dilakukan apabila telah selesai di implementasikan pada sistem.

7. Pemeliharaan, Tahapan yang terakhir ini adalah pemeliharaan untuk menjaga dan merawat sistem yang telah di implementasikan dan berjalan.

Penelitian mengenai viewboard ini memiliki 5 referensi yaitu diantaranya adalah sebagai berikut. Pada penelitian yang di terapkan pada Perguruan Tinggi Raharja mengenai viewboard sistem iRan (iLearning Raharja Ask and News) [1] yang memiliki masalah pada sistem sebelumnya karena data artikel laporan yang telah terbit belum terekap dengan baik, penelitian viewboard iRan bertujuan agar data tertata dengan baik sehingga dapat di tampilkan statistik keseluruhan artikel yang terbit. Selanjutnya penelitian tentang penerapan viewboard Go+ sebagai media monitoring pembayaran kuliah mahasiswa [2], pada penelitian ini bertujuan untuk menginformasikan data yang ada sehingga lebih akurat dan baik, dan berguna juga untuk memudahkan staff memonitoring semua yang berkaitan pengolahan data yang terdapata pada aplikasi Go+. Kemudian penelitian yang juga di lakukan pada Perguruan Tinggi Raharja [3], penelitian ini juga mengenai viewboard, yaitu optimalisasi viewboard pada sistem Rhjfox. Rhjfox merupakan suatu sistem forum sebagai media diskusi pada Perguruan Tinggi Raharja. Penelitian ini bertujuan untuk membantu pihak manajerial dalam mengambil keputusan berdasarkan keaktifan mahasiswa di Rhjfox, karena sebelumnya data informasi pada Rhjfox belum spesifik sehingga belum memberikan informasi yang cukup banyak. Penelitian selanjutnya tentang implementasi viewboard untuk mendukung penyebaran informasi yang di lakukan pada Perguruan Tinggi Raharja [4], penelitian ini membahas mengenai aplikasi viewboard yang bertujuan untuk membantu pengambilan keputusan, penelitian ini menggunakan database yang sudah ada pada sistem yang lain sebagai data warehouse. Selanjutnya, penelitian mengenai perancangan SIS+ pada Perguruan Tinggi Raharja [5], SIS+ ini bertujuan untuk memberikan informasi jadwal perkuliahan mahasiswa, tabel IPK, daftar nilai, kartu hasil studi dalam satu semester dan juga berbagai macam form untuk mengikuti kegiatan perkuliahan pada Perguruan Tinggi Raharja.

Dari lima Literature Review yang sudah di bahas, ada banyak penelitian yang berhubungan dengan penelitian yang penulis teliti mengenai viewboard. Karena pada sistem PESSTA+ belum di terapkan viewboard untuk memonitoring status validasi penilaian objektif, oleh karena itu penulis membahas hal "Penerapan Viewboard Status Validasi Berbasis Yii 
Framework pada PESSTA+ di Perguruan Tinggi”. Agar dapat memudahkan dosen dan mahasiswa mengetahui status validasi keseluruhan mahasiswa yang telah submit penilaian objektif pada sistem PESSTA+ guna memenuhi poin sebagai persyaratan sidang Skripsi.

\section{HASIL DAN PEMBAHASAN}

\subsection{Analisa Permasalahan}

PESSTA+ telah menjadi salah satu media submit secara online 10 Penilaian Objektif sidang dan di dalam sistem PESSTA+ juga terdapat Viewboard, salah satunya Viewboard status validasi Penilaian Objektif. Namun, semua data itu masih terlalu mentah untuk diolah karena data-data tersebut hanya berupa angka semata yang tidak memberikan informasi yang cukup banyak. Dengan banyaknya data namun kurangnya informasi, bisa menyebabkan kerugian yang cukup besar bagi pihak manajerial karena data tersebut belum bisa dijadikan acuan untuk mengambil sebuah keputusan. Informasi yang diberikan oleh sistem pun tidak begitu membantu. Hal ini menjadi dasar pemikiran rumusan masalah dalam penelitian ini adalah bagaimana mengolah data yang terdapat pada status validasi penilaian objektif menjadi sebuah viewboard yang menampilkan informasi akurat dan terkini yang berkaitan dengan penilaian objektif pada sistem PESSTA+, yang nantinya diharapkan dapat menjadi informasi monitoring status validasi penilaian objektif dalam mendata mahasiswa yang telah submit.

Karena banyaknya mahasiswa yang submit Penilaian Objektif pada sistem PESSTA+, maka ada banyak sekali data yang masuk dari keseluruhan nilai Penilaian Objektif. Pada sistem yang berjalan sebelumnya admin tidak dapat merekap data keseluruhan mahasiswa yang telah submit Penilaian Objektif. Dengan system sebelumnya juga belum ada informasi terkait status validasi penilaian objektif dan total keseluruhan mahasiswa yang telah submit pada PESSTA+. Gambar 3 menunjukkan penilaian objektif pada sistem PESSTA+.

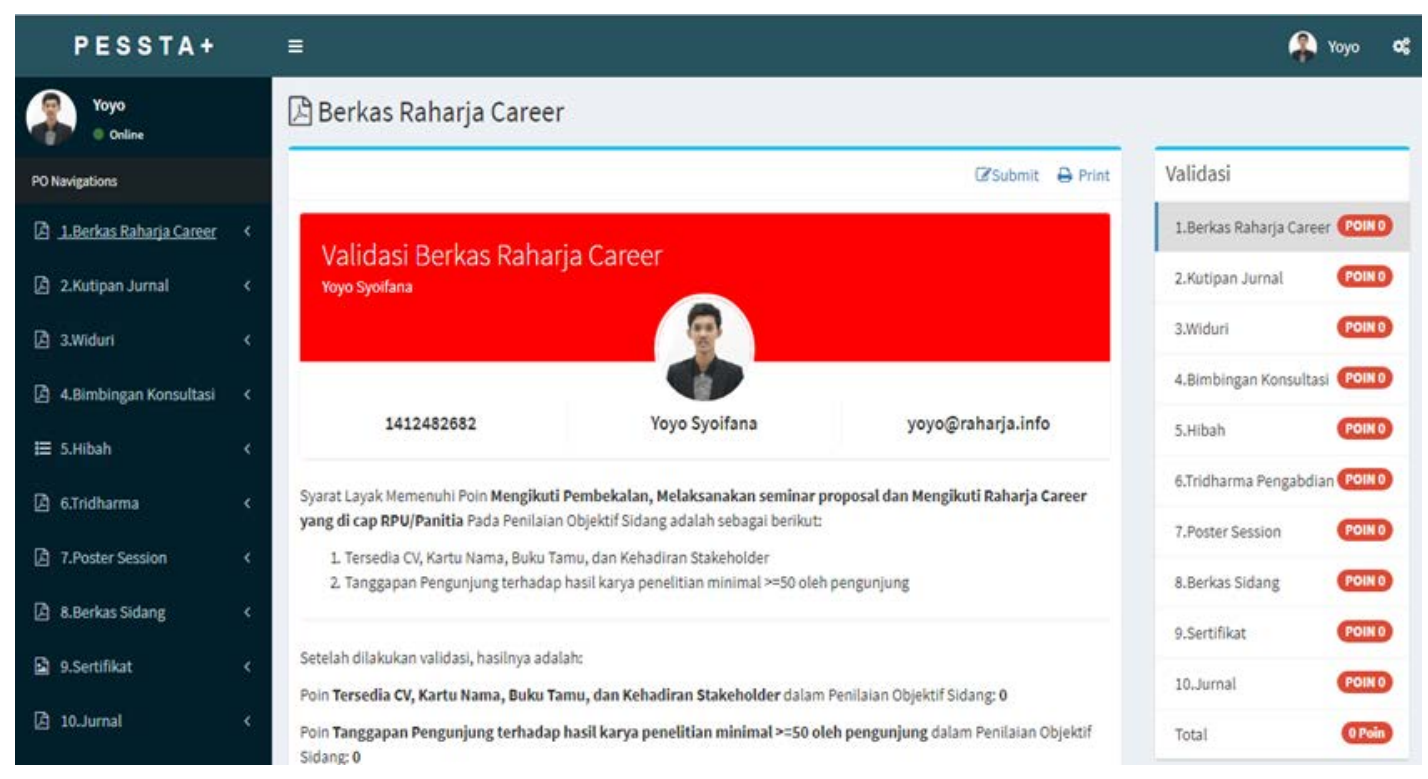

Gambar 3. Terdapat 10 Penilaian Objektif pada Sistem PESSTA+ 


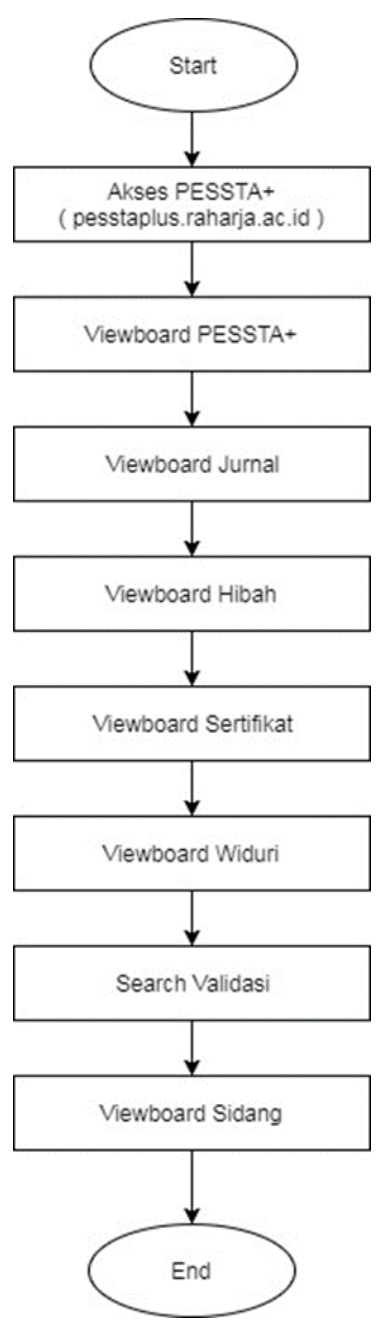

Gambar 4. Flowchart Sistem berjalan saat ini

Gambar 4 merupakan flowchart sistem yang berjalan yaitu terdiri dari:

1. Dua simbol titik terminal, yang di analogikan sebagai start dan finish pada proses program di menu search validasi penilaian objektif.

2. Delapan simbol proses yang menyatakan suatu proses yang di lakukan computer. Simbol proses diawali dengan akses PESSTA+, viewboard PESSTA+, viewboard sidang, viewboard penilaian jurnal, viewboard hibah, viewboard sertifikat, viewboard widuri, search validasi penilaian objektif, viewboard sidang.

\subsection{Pemecahan Masalah}

Untuk menyelesaikan permasalahan dari penelitian di atas, oleh karena itu di perlukan sistem yang dapat memberikan informasi yang menarik dalam bentuk chart dan tabel. Dalam penelitian ini penulis menggunakan salah satu komponen PHP yaitu Yii Framework sebagai kerangka dari perancangan sistem yang penulis lakukan, sehingga dapat menampilkan status validasi penilaian objektif dari keseluruhan mahasiswa yang telah submit dalam bentuk grafik dan tabel. 


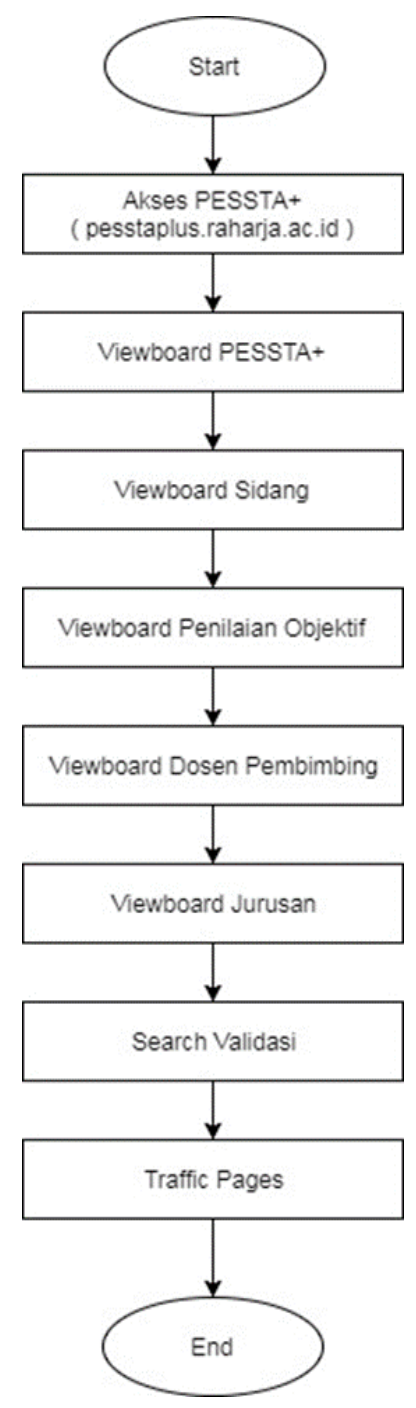

Gambar 5. Flowchart Sistem yang diusulkan

Gambar 5 merupakan flowchart sistem yang akan diterapkan terdiri dari:

1. Dua simbol titik terminal, yang dianalogikan sebagai start dan finish pada proses program di menu search validasi penilaian objektif.

2. Delapan simbol proses yang menyatakan suatu proses yang di lakukan computer. Simbol proses diawali dengan Akses PESSTA+, viewboard PESSTA+, viewboard sidang, viewboard penilaian objektif, viewboard dosen pembimbing, viewboard jurusan, search validasi penilaian objektif dan traffic pages. 
Citec Journal, Vol. 4, No. 4, Agustus 2017 - Oktober 2017

\begin{tabular}{|c|c|c|c|c|c|c|}
\hline VIEWBOARD PESSTA+ & & & & & & \\
\hline TAHUN ANAR 2016/2017 GENAP & Kode PO & Nama Po & Diterima & $\%$ Diterima & Ditolak & $\%$ Ditolat \\
\hline WO VB PENILALAN OBJEKTIF & PO 1 & $\begin{array}{l}\text { Mengikuti Pembekalan, Melaksanakan seminar proposal dan Mengikuti Raharja Career yang di cap } \\
\text { RPU/Panitia sbb: } \\
\text { a. Tersedia CV, Kartu Nama, Buku Tamu, dan Kehadiran Stakeholder. } \\
\text { b. Tanggapan Pengunjung terhadap hasil karya penelitian minimal }>=50\end{array}$ & $\begin{array}{l}113 \text { Mhs } \\
114 \text { Mhs }\end{array}$ & $\pi m$ & $\begin{array}{l}32 \text { Mhs } \\
31 \text { Mhs }\end{array}$ & 2396 \\
\hline \multirow{3}{*}{ ॠ VB JURUSAN } & $\mathrm{PO} 2$ & Terdapat minimal 5 kutipan dari jurnal nasional//lokal dan 5 kutipan dari jurnal internasional. & 103 Mhs & 715 & 42 Mhs & 2996 \\
\hline & PO3 & Laporan TA/Skripsi yang terdokumentasi di widuri dengan baik. & 101 Mhs & Es & 44 Mhs & 3196 \\
\hline & $\mathrm{PO} 4$ & Melakukan bimbingan konsultasi http://konsultasi,raharja.ac.id dengan pembimbing minimal $8 x$ & 99 Mhs & 65 & 46 Mhs & 324 \\
\hline \multirow{6}{*}{ WH TRAFIC PAGES } & POS & Hibah yang sudah diterima oleh Badan Negara atau crowd funding & 93 Mhs & 64 & 52 Mhs & $36 \%$ \\
\hline & PO6 & Memiliki Sertifikat Tridharma. & 69 Mhs & 415 & 76 Mhs & 5340 \\
\hline & PO7 & Menghasilkan Poster session. & 116 Mhs & $00 \%$ & 29 Mhs & 2046 \\
\hline & PO 8 & $\begin{array}{l}\text { Melengkapl kelengkapan berkas pendukung sidang sbb: } \\
\text { a. Menghasilkan Video presentasi Tugas Akhir/Skripsi durasi maksimal } 3 \text { menit } \\
\text { b. Mendapatkan Juara/penghargaan dalam pertandingan konteks ilmiah terdokumentasi. }\end{array}$ & $\begin{array}{l}105 \text { Mhs } \\
41 \text { Mhs }\end{array}$ & 2005 & $\begin{array}{l}40 \text { Mhs } \\
104 \text { Mhs }\end{array}$ & 2896 \\
\hline & POg & $\begin{array}{l}\text { Terdapat piagam/sertifikat seminar/Workshop/training IT } 6 \text { dari Kampus Raharja, } 3 \text { dari mahasiswa } \\
\text { dan } 1 \text { seminar Internasional. }\end{array}$ & 104 Mhs & $\pi \times$ & 41 Mhs & $29 \%$ \\
\hline & PO 10 & Menghasilikan artikel ilimiah atau lolos tahap reviewer yang dibuktikan secara online. & 72 Mhs & 405 & 73 Mhs & $51 \%$ \\
\hline
\end{tabular}

Gambar 6. Terdapat Tabel Status Mahasiswa yang tervalidasi

Gambar 6 menampilkan presentase diterima dan ditolaknya 10 poin penilaian objektif sebagai persyaratan sidang yang mahasiswa TA dan Skripsi submit agar dapat memudahkan melihat perbandingan setiap poin penilaian objektif sebagai persyaratan sidang yang ada.

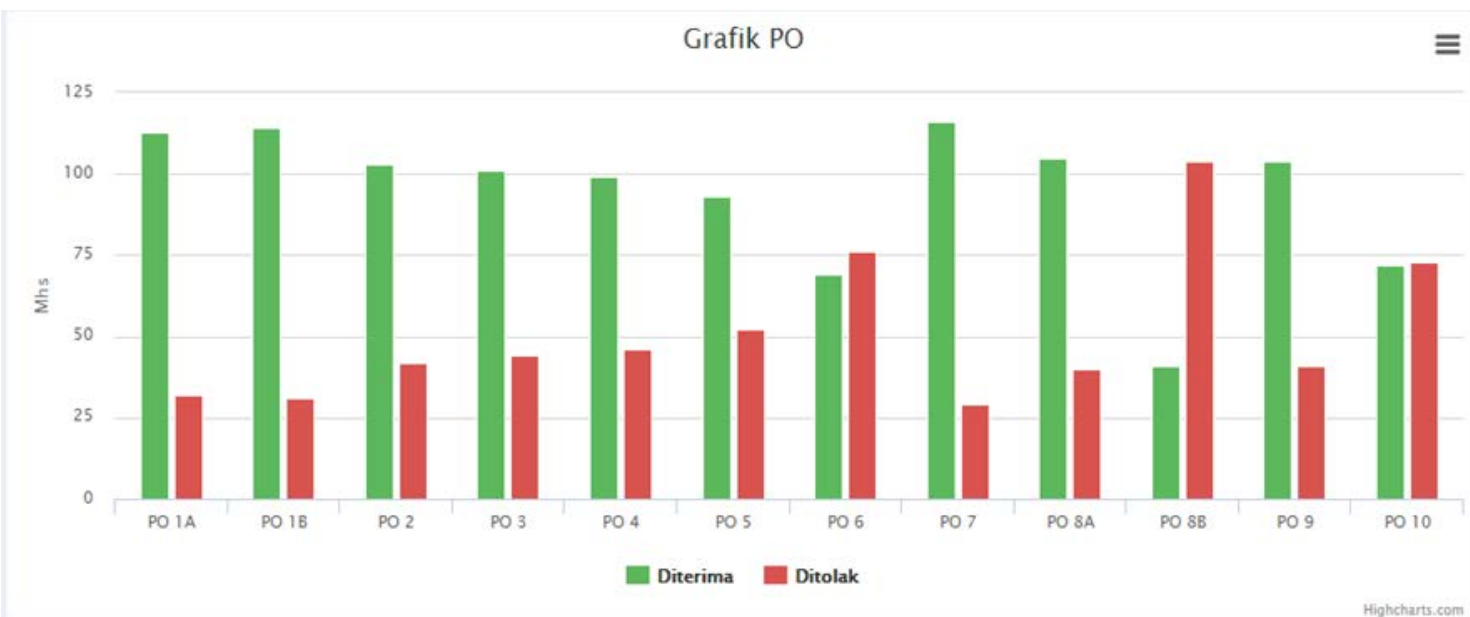

Gambar 7. Grafik Total Keseluruhan Mahasiswa Tervalidasi

Gambar 7 adalah grafik batang yang memudahkan dalam melihat presentasi di terima dan di tolaknya validasi pada keseluruhan Penilaian Objektif Sidang. Pada grafik di atas juga menampilkan status validasi dari 10 total keseluruhan Penilaian Objektif sebagai persyaratan Sidang Skripsi. 


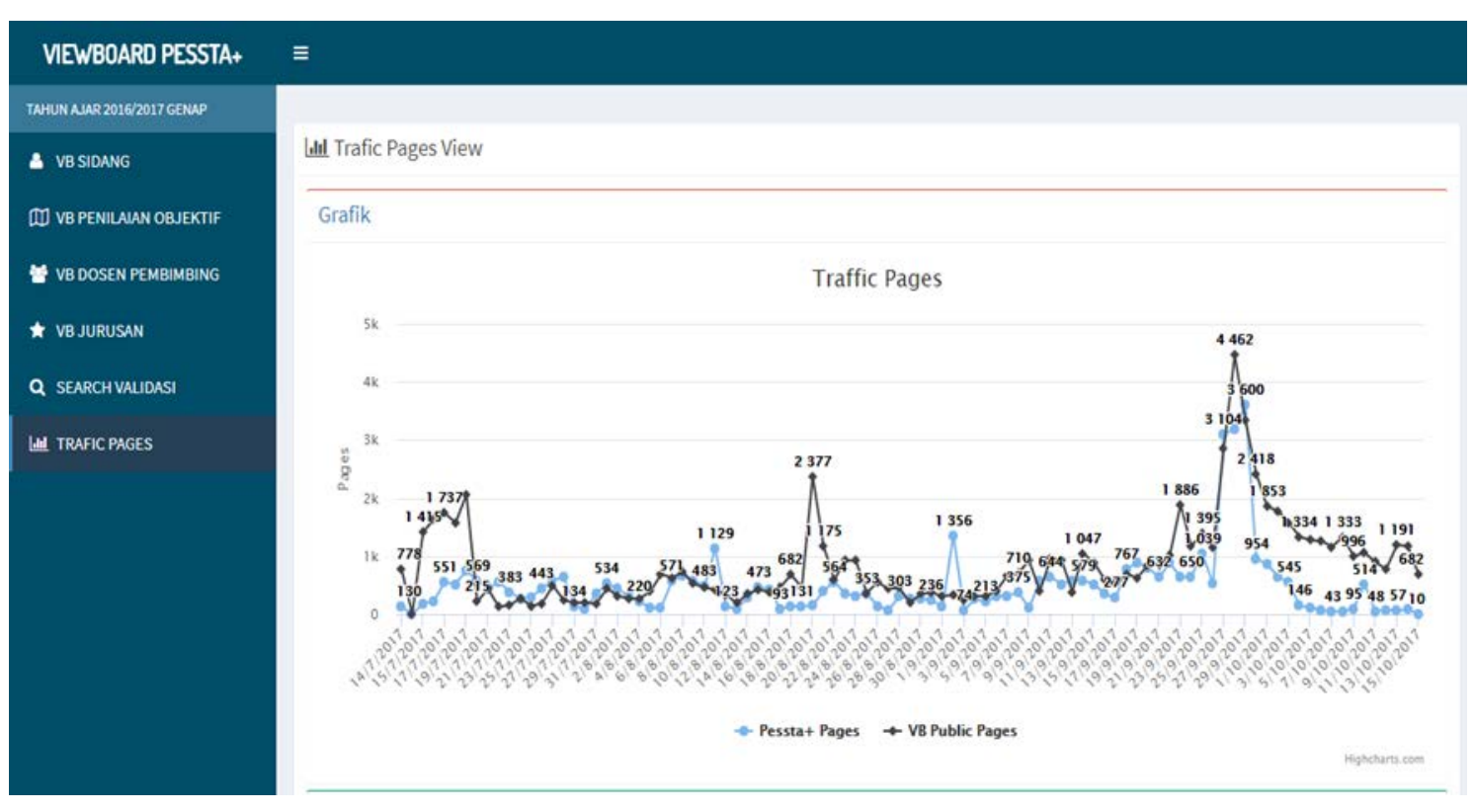

Gambar 8. Halaman Traffic Pages Viewboard

Dari Gambar 8 dapat dijelaskan bahwa tampilan halaman traffic pages di viewboard PESSTA+ berfungsi agar dapat melihat history click halaman viewboard PESSTA+. Dari traffic pages di atas dapat dilihat statistik history click pada sistem PESSTA+.

\section{KESIMPULAN}

Penerapan viewboard status validasi Penilaian Objektif pada sistem PESSTA+ memudahkan dosen maupun mahasiswa dalam memonitoring data mahasiswa yang telah submit dari 10 Penilaian Objekif Sidang yang di sajikan akurat, cepat dan efisien.

Dari perancangan yang telah penulis teliti dapat diambil kesimpulan bahwa dengan adanya viewboard diharapkan dapat memberikan informasi mengenai status validasi penilaian objektif. Jika sebelumnya pada viewboard PESSTA+ mahasiswa Skripsi hanya dapat melihat informasi diterima atau ditolaknya penilaian objektif sidang pada empat validasi yaitu jurnal, sertifikat, hibah dan widuri setelah dikembangkan viewboard PESSTA+ mahasiswa Skripsi dapat dengan mudah melihat informasi keseluruhan 10 poin penilaian objektif sebagai persyaratan sidang yang terdapat pada viewboard PESSTA+ sebelum pelaksanaan sidang dilaksanakan yang dibuat dengan menggunakan Yii Framework. Dengan adanya viewboard ini, dosen maupun mahasiswa dapat lebih mudah mendapatkan informasi total keseluruhan mahasiswa yang telah submit Penilaian Objektif.

\section{SARAN}

Dari pembahasan yang sudah di jelaskan pada penelitian di atas maka dapat penulis cantumkan saran yaitu sebagai berikut:

1. Diharapkan pihak pengembang selanjutnya menambahkan agar sistem memiliki history rekap data viewboard persemester, jadi agar dapat terlihat perbandingan dari viewboard semester sekarang dan semester-semester berikutnya.

2. Viewboard PESSTA+ dapat lebih dikembangkan supaya dapat memberikan informasi performa lebih detail lengkap. 
3. Diharapkan agar pihak pengembang selanjutnya dapat menambahkan agar sistem dapat memiliki viewboard untuk menampilkan data penilaian pembimbing dan juga penilaian dewan penguji.

\section{DAFTAR PUSTAKA}

[1] Rahardja, U., Pratama, D., Susanti, E., 2016, Implementasi Viewboard Dalam Mendukung Penyebaran Informasi Dengan Penyajian Artificial Informatics pada Perguruan Tinggi, JOURNAL CCIT, Vol. 9, No. 3, Hal 251-257.

[2] Rahardja, U., Handayani, I., Setiani, L., 2017. Viewboard Sebagai Laporan Jumlah Keseluruhan Artikel Pada iLearning Raharja Ask and News. CogITo Smart Journal, Vol. 3, No. 1, Hal 42-55.

[3] Handayani, I., Aini, Q., Oktaviani, F., 2016, Penerapan Sistem Validasi Jurnal di Pessta+ sebagai Penilaian Artikel Ilmiah Dalam Mendukung Kegiatan Civitas Akademika. CSRID (Computer Science Research and Its Development Journal), V. 8, No. 3, Hal 177-190.

[4] Rahardja, U., Tiara, K., Erviani, M. I., 2016. Optimalisasi Viewboard RHJFOX Berbasis Bootstrap Sebagai Sistem Penunjang Keputusan. Technomedia Journal, Vol. 1, No. 1, Hal 50-64.

[5] Tiara, K., Nurhaeni, T., 2016. Penerapan Viewboard GO+ Berbasis Yii Sebagai Media Monitoring Pembayaran Mahasiswa. Technomedia Journal, Vol. 1, No. 1, Hal 65 - 77.

[6] Warsito, A. B., Yusup, M., Makaram, I., 2015. Perancangan SIS+ Menggunakan Metode YII Framework Pada Perguruan Tinggi Raharja. CCIT Journal, Vol. 8, No. 2, Hal 24 - 33.

[7] Riyanto, 2015. Validasi \& Verifikasi Metode Uji: Sesuai Dengan Iso/Iec 17025 Laboratorium Pengujian Dan Kalibrasi. Deepublish, Yogyakarta.

[8] Rahardja, U., Pratama, D., Susanti, E., 2016. Implementasi Viewboard Dalam Mendukung Penyebaran Informasi Dengan Penyajian Artificial Informatics Pada Perguruan Tinggi. CIT Journal, Vol. 9, No. 3, Hal 251-257. 